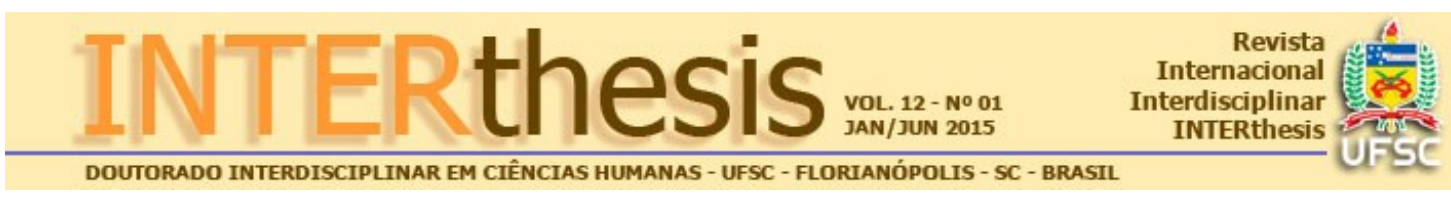

\title{
DINÂMICAS TERRITORIAIS E SOCIEDADE: UMA EXPERIÊNCIA DE PÓS- GRADUAÇÃO INTERDISCIPLINAR NA AMAZÔNIA
}

Hildete Pereira dos Anjos ${ }^{1}$

Fernando Michelotti ${ }^{2}$

\section{Resumo:}

Este trabalho apresenta uma experiência inicial de um programa de pós-graduação na região norte do Brasil. Para tanto, apresenta as bases conceituais do programa, uma leitura do contexto regional e, com base em análise documental, uma primeira reflexão sobre as temáticas abordadas pela primeira turma de mestrandos. A proposta do programa é estudar, num enfoque interdisciplinar, as dinâmicas territoriais que conformam a região. As temáticas tratadas enfocam as dinâmicas socioeconômicas em relação com o poder local, as políticas públicas, os grandes projetos, os movimentos de resistência e os saberes e discursos produzidos nessas relações.

Palavras-chave: Interdisciplinaridade. Dinâmicas Sociais. Território. Amazônia.

\section{INTRODUÇÃO}

Esse trabalho pretende analisar a coerência interna do Programa de PósGraduação em Dinâmicas Territoriais e Sociedade na Amazônia (PDTSA), tomando como corpus analítico os projetos de sua primeira turma. Estudiosos têm chamado a atenção para a necessidade de se formar e enraizar pesquisadores na região Norte. Nesta direção, Val (2006, p.42) alertava para a importância de criar novas universidades na Amazônia e ampliar o número de doutores nessas instituições. Apontava como uma "luz no fim do túnel" o fato de que "novos programas de pósgraduação vêm sendo instalados na Amazônia".

De fato, observa-se um crescimento exponencial da pós-graduação (de responsabilidade federal) na região ${ }^{3}$, mas isso significa muito pouco ainda para a sua interiorização. Cabe observar que, dentro do movimento recente de crescimento

\footnotetext{
1 Doutora em Educação pela Universidade Federal da Bahia. Professora na Faculdade de Educação e no Programa de Pós-Graduação em Dinâmicas Territoriais e Sociedade na Amazônia na Universidade Federal do Sul e Sudeste do Pará, Instituto de Ciências Humanas, Marabá, PA, Brasil. E-mail: dosanjoshildete@gmail.com

${ }^{2}$ Mestre em Planejamento do Desenvolvimento com ênfase em Economia do Desenvolvimento pela Universidade Federal do Pará. Professor adjunto da Universidade Federal do Sul e Sudeste do Pará, Marabá, PA, Brasil. E-mail: fmichelotti@ufpa.br

${ }^{3}$ Conforme dados da CAPES (disponíveis em www.capes.gov.br./cursos-recomendados ), a região norte conta atualmente com 190 programas de pós-graduação, dos quais 152 em universidades federais.
}

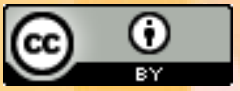


da pós-graduação na região norte, a interiorização é um movimento recentíssimo. 0 primeiro programa de pós-graduação instalado fora das sedes das universidades divulgou seu edital no ano de $2006^{4}$.

O Programa Dinâmicas Territoriais e Sociedade na Amazônia iniciou sua primeira turma de mestrado em 2012, ainda através da UFPA (Campus de Marabá) 5 . Maior universidade da região norte, quando da criação do PDTSA a UFPA já contava com cinquenta e quatro programas de pós-graduação, incluindo três em Campi do interior. Tratava-se do terceiro mestrado da instituição com uma proposta interdisciplinar, o que evidenciava o desafio de contribuir para a ampliação do espírito de interdisciplinaridade numa tradição de formação solidamente disciplinar; ao mesmo tempo, o mestrado apresentava uma ênfase no estudo das dinâmicas territoriais, nas relações e imbricações entre os diversos processos sociais, econômicos, culturais (em suas múltiplas dimensões) que configuram uma região. Este artigo se propõe a analisar, nas temáticas tratadas nos projetos de mestrandos, a experiência em seu nascedouro; para tanto, apresentamos uma breve descrição do contexto histórico da região, explicitamos os conceitos que the dão sustentação, a saber, interdisciplinaridade e território, para analisar os modos como tais temáticas se interpenetram nas linhas de pesquisa e nos trabalhos a elas vinculados.

\section{METODOLOGIA}

Para o trabalho analítico, adotamos a pesquisa documental, compreendendo que, para os propósitos deste estudo, os projetos de pesquisa selecionadas pelo Programa deveriam apresentar indícios claros de pertencimento não apenas às temáticas de pesquisa assumidas (no caso, as dinâmicas territoriais na Amazônia), mas também determinado potencial de trabalho interdisciplinar. Consideramos tais materiais como fonte primária, entendida como "materiais que ainda não receberam tratamento analítico" (SÁ-SILVA, ALMEIDA e GUINDANI, 2009).

O corpus para análise constituiu-se dos doze projetos de pesquisa da primeira turma de mestrado (cuja formação se iniciou em 2012), incorporando as

\footnotetext{
${ }^{4}$ Programa de Pós-Graduação em Produção Vegetal, da UFT, no Campus de Gurupi (TO).

${ }^{5}$ No segundo semestre de 2012 foi criada a Universidade Federal do Sul e Sudeste do Pará, a partir do Campus de Marabá da UFPA, e o Programa em análise passou a ser o seu primeiro programa de pós-graduação.
}

R. Inter. Interdisc. INTERthesis, Florianópolis, v.12, n.1, p.209-227, Jan-Jun. 2015 
modificações sofridas até o momento de qualificação. Em cada projeto, foram recortados o problema de pesquisa e os objetivos; as temáticas presentes foram então cotejadas com a ementa das duas linhas de pesquisa do programa, num exercício de análise de conteúdo (BARDIN, 1979).

\section{ELEMENTOS PARA UM DEBATE INTERDISCIPLINAR SOBRE AS DINÂMICAS TERRITORIAIS}

Interdisciplinaridade é um conceito cuja polissemia evidencia a existência de embates no campo epistemológico. Fazenda (1984) num estudo sobre a trajetória do conceito, afirma que a década de 70 é marcada pela busca da definição de interdisciplinaridade, enquanto que na década de 80 o foco é na busca pelo método e, em 90, tentou-se produzir uma teoria da interdisciplinaridade. Os principais elementos que, neste trabalho, incorporamos desse esforço é que a cisão das dinâmicas territoriais em fragmentos disciplinares implicaria na perda de seu movimento interno, de sua rede de relações. Não se trata, portanto, nem de estabelecer pontes entre disciplinas a partir de um problema, nem de preencher vazios nas ciências existentes, propondo novas disciplinas, ou novas estruturações para o conhecimento acadêmico (LENOIR, in FAZENDA, 1998, p.56), mas de compreender, com Frigotto (2008, p. 43), que

\footnotetext{
$\mathrm{Na}$ medida em que o conjunto das ciências sociais e humanas (...) tem como objeto de conhecimento a compreensão e explicitação da produção da existência social dos homens, não há razões de ordem ontológica e epistemológica para cindir autonomamente esta ou aquela prática social.
}

No mesmo texto, Frigotto ( 2008, p. 42, grifos do autor) defende que "trata-se de apreender a interdisciplinaridade como uma necessidade (algo que historicamente se impõe como imperativo) e como problema (algo que se impõe como desafio a ser decifrado). Ou seja, longe de ser um modismo, a perspectiva interdisciplinar se impõe pelas próprias concepções de pesquisa e configuração do objeto a ser pesquisado.

Leis (2006), amparando-se em Klein, distingue entre canais tradicionais e inovadores no desenvolvimento do espírito interdisciplinar. Os primeiros estariam associados à busca de uma síntese para o conhecimento, numa busca de superação da fragmentação própria do modelo disciplinar e de expansão das 
fronteiras disciplinares, num esforço de redefinição paradigmática. Os segundos envolveriam experimentos, modos de lidar com questões que não podem mais ser respondidas pelos limites das disciplinas, mas que não exigem a construção prévia de um paradigma.

Pode-se dizer que as questões colocadas pelas dinâmicas territoriais, em nossa perspectiva, têm essa característica comum: exigem não apenas a mobilização de conhecimentos produzidos nos diversos campos disciplinares, mas também sua imbricação com saberes não reconhecidos no mundo acadêmico, e isso vai se fazendo de modo experimental, aos tateios. Exigem, ainda, o esforço de esgarçamento das fronteiras disciplinares, mas para dialogar com esses saberes e com seus modos de chegar a verdades, que diferem entre si e diferem do modo disciplinar. Nesse segundo sentido, não deixam de buscar sínteses, ainda que as tomando como provisórias e sem a intenção de chegar a um "quadro conceitual global que poderá, numa ótica de integração, unificar todo 0 saber científico"(LENOIR, in FAZENDA, 1998, p.48).

$\mathrm{Na}$ proposta de pós-graduação em análise, os muitos saberes (disciplinares ou não) são tomados em sua historicidade, em sua contingencialidade. As noções advindas dos campos disciplinares nos amparam por um lado, na construção e reconstrução nas questões colocadas, mas por outro, abrem novas questões. Os saberes das comunidades locais, de seus agentes, das organizações a elas vinculadas, não apenas ajudam na percepção dos limites da visão disciplinar, mas, como foi dito, colocam outras estratégias de construção de verdades. Conforme Santos, "o reconhecimento da diversidade epistemológica do mundo sugere que a diversidade é também cultural e, em última instância, ontológica, traduzindo-se em múltiplas concepções de ser e estar mundo" (2008, p.142). No mesmo texto, Santos descreve interdisciplinaridade como "uma forma de colaboração que pressupõe o respeito pelas fronteiras entre disciplinas tais como elas existem", caracterizando essa relação como "uma relação policiada" (op. cit., p.147) e argumentando que ela não poderia gerar novos objetos, novas interrogações, novos problemas. É verdade que as definições tradicionais de interdisciplinaridade não incorporam os "outros saberes" de que trata Santos. Se mantivemos o conceito como base para nosso projeto, subvertendo seus sentidos já dados, é porque reconhecemos que esta proposta ainda tem a relação entre campos disciplinares como uma característica 
forte, mas avança tanto na direção de esgarçamento das fronteiras disciplinares quanto do reconhecimento e incorporação de uma diversidade epistemológica.

Desse modo, o exercício da interdisciplinaridade e a consequente reelaboração do conceito, na produção de um programa que assume isso como uma de suas dimensões, implicará em colocar saberes disciplinares em encontro e em confronto, trazer outros saberes antes ocultados ou desvalorizados (porque periféricos ou dominados) para esse diálogo; trazer também, como aponta Santos (2008, p.157), "ignorâncias", "desconhecimentos", produzidos na escolha de certos saberes como verdadeiros e no ocultamento de outros. Esse exercício da interdisciplinaridade nos parece relevante para o tratamento da temática principal desse Programa de Pós-Graduação: as dinâmicas territoriais e a sociedade na Amazônia, justamente pelo caráter multidimensional da noção de território.

O conceito de território também é polissêmico, expressando diferentes concepções. Haesbaert (2011) propõe agrupar tais concepções a partir de seu posicionamento em relação a dois conjuntos de perspectivas: materialismoidealismo e espaço-tempo. Com relação à primeira polarização, Haesbaert (2004) aponta concepções naturalistas, econômicas, políticas, simbólicas; afirma que em cada uma delas predomina uma visão parcial de território, enfatizando uma dimensão principal ou determinante na explicação do território, seja ela 'natural', econômica, política ou cultural. Como contraponto, o autor defende a perspectiva de uma perspectiva integradora, tendo como base a concepção de que o território carrega de forma indissociável uma dimensão simbólica ou cultural e uma dimensão material, de natureza econômico-política, as quais não podem ser tratadas isoladamente. Para o autor, privilegiar uma dessas dimensões se ancora nos recortes disciplinares, cabendo à geografia desenvolver essa visão integradora.

Outra questão que deve ser observada na construção de uma visão integradora do território refere-se ao binômio espaço-tempo. Para Haesbaert (2004), as diferentes concepções de território tanto oscilam entre um sentido mais absoluto (território como objeto) ou relacional (território como teia de relações), como possuem uma historicidade e uma geograficidade.

Com base nessas considerações, Haesbaert (2004) defende a leitura do espaço como um híbrido entre sociedade-natureza, política-economia-cultura, materialidade-idealidade, numa complexa interação tempo-espaço e na 
indissociação entre movimento e (relativa) estabilidade. Nessa perspectiva híbrida, "o território pode ser concebido a partir da imbricação de múltiplas relações de poder, do poder mais material das relações econômico-políticas ao poder mais simbólico das relações de ordem mais estritamente cultural" (p. 79)

Numa concepção de território que toma como ponto de partida a continuidade no espaço, uma análise que leve em conta tantas dimensões fica limitada. Torna-se heurística, no entanto, se os territórios são entendidos como articulados em rede através de múltiplas escalas, evidenciando a importância das análises multiescalares e da conformação dos chamados territórios-rede. Para o próprio Haesbaert (2004), essa visão ampla de território, em que as relações de poder não ficam restritas ao Estado, integradora de múltiplas dimensões e com um sentido relacional, definido sobretudo com referência às relações sociais (ou culturais, em sentido amplo) e ao contexto histórico em que está inserido, aproximase do conceito de espaço geográfico proposto por Milton Santos, entendido como território usado, "mediação entre o mundo e a sociedade local e nacional" (SOUZA, M. A, 2005, p 253). "O território são formas, mas o território usado são objetos e ações, sinônimo de espaço humano, espaço habitado" (SANTOS, M., 2005, p. 255)

Milton Santos propõe uma atualização do conceito de território incorporando noções como lugar, contiguidade, verticalidade, horizontalidade, espaço banal.

\begin{abstract}
Isso é o resultado da nova construção do espaço e do funcionamento do território, através daquilo que estou chamando de horizontalidades e verticalidades. As horizontalidades serão os domínios da contiguidade, daqueles lugares vizinhos reunidos por continuidade territorial, enquanto as verticalidades seriam formadas por pontos distantes uns dos outros, ligados por todas as formas e processos sociais (p. 256).
\end{abstract}

Essa elaboração permite que o autor contraponha à noção de rede, associada aos processos de mundialização ou globalização (às verticalidades, portanto) a noção de espaço banal (trazida de Francois Perroux): "o espaço de todos, todo o espaço, porque as redes constituem apenas uma parte do espaço e o espaço de alguns" (p. 256). Os mesmos espaços podem ser pensados como domínios da horizontalidade e da verticalidade, mas contendo funcionalidades diferentes em cada caso: "acontecendo" simultaneamente de modos diferentes e, às vezes, divergentes, para cada relação. Esse acontecer simultâneo, em diferentes escalas e em diferentes relações no que se refere ao domínio da técnica e da política, cria "a possibilidade do acontecer solidário, malgrado todas as formas de diferença, entre 
pessoas, entre lugares" (p.256). Esse acontecer solidário, considerados os conflitos entre espaço local e espaço global, exige o lugar como sede da resistência, mas sem perder de vista as possibilidades do uso das redes como criação de novas horizontalidades. Milton Santos chama a atenção, enfim, para a importância do tratamento analítico do território como aspecto fundamental do modo como tem se produzido o real na contemporaneidade.

Assumir tal concepção implica em pensar as relações sociais como produtoras de espaços fragmentados e conflitivos (FERNANDES, 2005). O espaço como fragmento é uma representação construída a partir de uma intencionalidade da relação social que o criou e que passa a expressar uma totalidade (mesmo sendo parcial) que, em função de uma forma de poder e do campo de forças em disputa, pode se tornar dominante. Assim, Fernandes (2005) utiliza a noção de território como um espaço apropriado por determinadas relações sociais que o produzem e o mantém a partir de formas de poder. Essas definições levam Fernandes a enfatizar que a produção de espaços e territórios se dá em movimentos "desiguais, contraditórios e conflitivos" (2005, p.28);

Imbricação de múltiplas relações de poder, em Haesbaert (2004, 2011); espaço usado em relações de contiguidade ou em rede, produto de múltiplas totalizações, em Milton Santos (2005), produção do enfrentamento no uso do espaço, em Fernandes (2005), a noção de território aqui mobilizada permite a leitura interdisciplinar das dinâmicas regionais a que se propõe o programa de pósgraduação cuja produção inicial está em estudo. Os saberes disciplinares acerca do lugar não deixarão de ser mobilizados, mas não poderão deixar de ser problematizados em suas inter-relações; as leituras do "espaço banal" obrigam à assunção de saberes dominados, invisibilizados ou desvalorizados; a análise de inter-relações entre verticalidades e horizontalidades permite evidenciar desconhecimentos, ocultamentos, processos de invisibilização, tanto de formas de conhecer como de modos de produzir a existência.

\section{DINÂMICAS TERRITORIAIS NA AMAZÔNIA}

Analisando as dinâmicas territoriais amazônicas, do ponto de vista histórico, Becker (2006, p. 23) propõe uma periodização em três fases distintas. Na primeira 
fase ganha destaque o "boom" da borracha ocorrido entre 1850 e 1920 (WEISTEIN,1993; SANTOS, 1980; DEAN 1989), não desconsiderando a existência de outros elementos marcantes da ocupação econômica, no período das chamadas 'drogas do sertão' pré-1850 e da des-reestruturação do sistema extrativista da borracha, após 1920, com a formação de outros sistemas de exploração extrativistas sub-regionais, como o do extrativismo da castanha e do diamante na região de Marabá.

Becker (op. cit., p. 24) observa, nessa primeira fase, três elementos fundantes da problemática amazônica: a ocupação tardia e dependente do mercado externo, a importância da geopolítica e a experiência e o confronto de modelos de ocupação territorial. Esses elementos traduzem-se por um processo de ocupação da região financiado e dirigido por interesses do capital externo, conformando uma periferia da economia-mundo capitalista com uma ocupação colonial e posteriormente nacional baseada no controle de pontos estratégicos, sobretudo as embocaduras dos grandes rios. Esse modelo hegemônico, no entanto, foi permanentemente tensionado pelo confronto com outra perspectiva mais endógena de ocupação, baseada numa visão interna do território a partir das populações locais.

$\mathrm{Na}$ segunda fase da periodização, ganha destaque a Operação Amazônia, que entrou em vigor em 1966. Essa ação estatal na Amazônia deu-se articulada com mudanças fundamentais no padrão de acumulação capitalista brasileiro, com a superação da fase da 'industrialização restringida' pela 'industrialização pesada' baseada na implantação de um setor de bens de produção financiado pelo Estado e pela empresa oligopolista internacional (MELLO, 1982).

Os estudos sobre os chamados 'grandes projetos' na Amazônia (CASTRO et al., 1995), demografia e migração (ARAGÓN e MOUGET, 1986), dinâmicas de fronteira (VELHO, 1972; MARTINS, 1981; HÉBETTE, 2004), colonização na Amazônia (IANNI, 1979), violência (ALMEIDA, 1991) e os impactos socioambientais desse processo (HECHT e COCKBURN, 1990; SCHMINK e WOOD, 1992) demarcaram uma reflexão crítica sobre esse período, consonante com o movimento social pelo fim da ditadura e pelo restabelecimento da democracia no país.

O ano de 1985, início da terceira fase da periodização de Becker (2006), explicita as marcas da crise do Estado e do projeto nacional-desenvolvimentista e da resistência social em todo o país. Na Amazônia, as maiores expressões dessa 
resistência social foram protagonizadas por novos movimentos sociais com forte viés identitário, que Gonçalves (2001) caracteriza como movimentos de r-existência, posto que não apenas fazem uma luta de resistência, mas lutam pela possibilidade de uma determinada forma de existência, um modo de vida e de produção, por modos diferenciados de sentir, agir e pensar. Identidades como seringueiros, quilombolas, ribeirinhos e indígenas ganharam dimensão política, com forte apoio nacional e internacional, no contexto da emergência de um movimento ecológico com grandes preocupações com o desmatamento da Amazônia.

Essa mudança de período, para Costa (1992) apresenta uma mudança ideológica importante na Amazônia: a 'ideologia agrária' que havia sido hegemônica em todo o período anterior passa a ser fortemente questionada por uma nova 'ideologia extrativista', portadora de uma preocupação com os aspectos socioambientais do desenvolvimento. Contraditoriamente, a emergência dessa 'ideologia extrativista' se deu num contexto em que o extrativismo vegetal havia sido superado economicamente por um outro padrão de ocupação, em que a pecuária extensiva e a mineração industrial tinha se enraizado fortemente na região. Acirrouse a disputa de projetos e modelos de desenvolvimento na região, sobretudo no agrário, tendo de um lado uma perspectiva baseada na racionalidade industrialista e na homogeneização e simplificação da natureza e de outro a racionalidade camponesa / extrativista e o uso sustentável da sóciobiodiversidade. Para Costa (2005) essa tensão também envolve diferentes perspectivas de atuação do Estado e de sua institucionalidade, refletindo nas disputas pelas concepções de políticas fundiárias, creditícias e ambientais.

Esse novo contexto insere-se no período de emergência da chamada globalização neoliberal. A crise do Estado e do projeto nacional-desenvolvimentista, em escala mundial, levou a uma ascensão de uma perspectiva liberal materializada em programas de estabilização com reformas estruturais, voltadas à desregulamentação dos mercados, à privatização e à redução do papel do Estado (FIORI, 1993). Ao mesmo tempo, esse movimento de globalização fortaleceu, em escala mundial, uma perspectiva de superexploração dos recursos naturais (matérias primas e energia), intensificando o grau de exploração predatória da região amazônica. Mesmo o projeto baseado no uso sustentável da sociobiodiversidade, que se contrapôs ao macroprojeto de integração subordinada à 
globalização neoliberal, também foi influenciado por este contexto. Brandão (2007) critica a perspectiva excessivamente localista desse projeto nesse período, por centrar todas as possibilidades de sucesso nas vontades e iniciativas de uma comunidade empreendedora e solidária atuando na escala local, desconsiderando classes sociais, oligopólios e hegemonias.

Esse movimento econômico desdobrou-se também no campo das políticas de desenvolvimento regional, tanto do ponto de vista da privatização $e$ desregulamentação da exploração dos recursos naturais minerais, florestais e energéticos, como do ponto de vista da perspectiva localista de fomento ao desenvolvimento sustentável. Essas tensões e contradições permanecem atuais na formulação das políticas de Estado e na sua implementação na Amazônia.

\section{AS DINÂMICAS TERRITORIAIS EM ANÁLISE NA EXPERIÊNCIA INICIAL}

O programa de pós-graduação delineia, como grande foco de investigação, as dinâmicas das relações sociais nesta região, no contexto da expansão do capital, procurando compreender essa dinâmica analisando relações entre as dimensões econômica, política e sociocultural. As duas linhas de pesquisa que integram o programa (Linha 1, denominada Estado e Dinâmicas Sócioambientais e Linha 2, denominada Produção Discursiva e Dinâmicas Territoriais e Sociedade na Amazônia) assim definem esse projeto, em suas ementas:

\footnotetext{
Linha 1: Investiga a região amazônica nas suas dinâmicas sociais, políticas, econômicas ambientais e culturais em sua interatividade com os aspectos globais e regionais da expansão do capital. Analisa as relações entre Estado e sociedade e entre sociedade e natureza, investigando impactos nos processos produtivos agrários e industriais, nas relações sociais de produção e na formação para o trabalho. Estuda formas de ação coletiva, práticas de resistência política, cultural e produtiva e suas implicações na formulação e implementação das políticas públicas.

$[\ldots]$

Linha 2: Estuda representações discursivas das relações que se instauram nas dinâmicas sociais, políticas, ambientais e culturais na Amazônia. Investiga, nessa heterogeneidade discursiva, tensões produzidas no jogo das relações de poder e de resistências ou emancipação. Analisa discursos produzidos em esferas institucionais e não institucionais, considerando as contradições próprias das relações entre as dinâmicas socais e as formações ideológicas (UFPA, 2012).
}

Não trataremos aqui daquilo que distingue as duas linhas, de resto bastante explícito nas definições acima. Interessa, para este trabalho, analisar a relação que as temáticas apresentam com as dinâmicas territoriais, assim como seu potencial de R. Inter. Interdisc. INTERthesis, Florianópolis, v.12, n.1, p.209-227, Jan-Jun. 2015 
trabalho interdisciplinar. Tratando das temáticas que são assumidas como dinâmicas territoriais, o corpus traz como temas o lugar das políticas públicas, os saberes das comunidades, agentes e organizações locais na produção da resistência aos grandes projetos, a relação entre movimentos de resistência e mídia, relações entre os grandes projetos, trabalho e migração, poder local, assim como configurações específicas deste último, como o discurso separatista regional e o discurso de revalorização da natureza.

As políticas públicas aparecem como objeto de análise em relação com os modos de ocupação do território nos assentamentos urbanos informais (RUSSI, 2012), com as lógicas produtivas da agricultura familiar regional (BRESSAN, 2012) e com os currículos da educação profissional em relação com os grandes projetos (MARTINS, 2012).

Os processos socioeconômicos produzidos na relação com os grandes projetos aparecem nos projetos de Ikeda (2012), que analisa os modos como o desenvolvimento recente da região reconfigura a organização do poder político local, de Bezerra (2012), cujo trabalho enfoca os impactos da terceirização no processo de trabalho em Carajás e de Souza, A. (2102), cujo interesse é o processo migratório de trabalho maranhense na conformação da dinâmica territorial do município de Parauapebas.

Os saberes locais, organizados a partir de projetos de resistência, emergem no trabalho já citado de Bressan (2012), que analisa o ponto de vista das cooperativas ligadas à agricultura familiar acerca do Programa Nacional de Alimentação Escolar (PNAE) no qual estão envolvidas, no trabalho de Ribeiro Jr. (2012), que enfoca a constituição da identidade do povo Akrãtikatêjê, a partir dos processos de dominação e resistência, assim como num estudo das percepções de território das mulheres quebradeiras de coco de São Domingos do Araguaia (SOUZA, V., 2012) e outro acerca das formas de organização social de ribeirinhos diante de um projeto hidroelétrico (SILVA, 2012).

A relação entre resistência e mídia é enfocada por Sena (2012), ao analisar os discursos produzidos pela imprensa escrita local acerca do Movimento dos Trabalhadores Rurais Sem Terra (MST), e a mesma mídia, de outro ponto de vista, é estudada por Lisbôa (2012), num estudo dos recursos discursivos utilizados nas propagandas eleitorais do plebiscito para a divisão do Pará, ocorrido em 2011. 
As relações entre sociedade e natureza são o foco do trabalho de Teixeira Jr. (2012), numa análise da criação do projeto "Município Verde" em Paragominas, buscando estudar a incorporação de um "discurso verde" às iniciativas de desenvolvimento ancoradas numa perspectiva da homogeneização da natureza.

Esse grupo de temas de pesquisa propõe a leitura de um território em uso, antevendo relações de enfrentamento e produção de resistências. A emergência de novos movimentos sociais com viés identitário, como analisava Gonçalves (2001) aparece no trabalho de Sena (2012), cujo foco é o MST, olhado através dos discursos da mídia, tal como no de Ribeiro Jr. (2012), enfocando lideranças indígenas Akrãkikatêjê. Ribeirinhos e quebradeiras de coco ganham destaque nas pesquisas de Silva (2012) e Souza, V. (2012), respectivamente. Assim, fortalecem uma análise dos processos de re-existências e movimentos de produção do território a partir da ação local, mas nas relações com as coerções de verticalidades produzidas pela globalização.

Os grandes projetos (assumidos como verticalidades), também apontados na análise prévia das dinâmicas territoriais como um componente importante para uma leitura das características das dinâmicas sociais na região, são enfocados nos trabalhos de Martins (2012), Ikeda (2012), Bezerra (2012) e Souza (2012). Neles, os aspectos destacados para estudo são as interações com o poder local e a relação capital/trabalho, expressando as diferentes formas de poder que produzem, de forma desigual, o território, bem como das dinâmicas de desterritorializaçãoreterritorialização, evidenciados pelos os processos migratórios que caracterizam a ocupação da região. Tais escolhas temáticas indicam que os estudos sobre dinâmicas territoriais deverão levar em conta os modos de produção da vida e as contradições entre eles próprios e tais dinâmicas, atentos aos movimentos desiguais, contraditórios e conflitivos "pelo estado permanente de enfrentamento de forças políticas que procuram criar, conquistar e controlar seus territórios", como destacava Fernandes (2005, p.30).

\section{CONCLUSÕES}

Todos esses estudos, evidentemente, só fazem sentido se referidos a processos mais gerais de organização social e econômica, de proposição das R. Inter. Interdisc. INTERthesis, Florianópolis, v.12, n.1, p.209-227, Jan-Jun. 2015 
políticas e de produção e circulação de sentidos. A perspectiva excessivamente localista do desenvolvimento regional que criticava Brandão (2007) também é um risco no campo acadêmico. As propostas de pós-graduação ancoradas numa realidade específica, como é o caso em análise, precisam tratar dos processos globais que influenciam na formulação das políticas, na relação capital/trabalho (pensando pelo viés das verticalidades), mas também nas perspectivas educacionais e culturais, no movimento de produção e reprodução da vida em termos locais.

Levantado o modo como as temáticas se articulam entre si e na relação com a proposta do programa, cabe destacar seu potencial de trabalho interdisciplinar, entendendo-se o conceito como uma construção em aberto, para além do diálogo entre as disciplinas, cuidando de contribuir no esgarçamento de suas fronteiras. Isso se evidencia na busca de incorporação de saberes e pontos de vista de sujeitos e organizações sociais locais, no deslocamento dos saberes disciplinares para os seus limites ao se encontrar com os saberes locais, no fato de que seu foco se coloca em questões prementes para o entendimento das dinâmicas regionais. Tal movimento incorpora a preocupação de Santos com a construção de uma diversidade epistemológica, que implica em colocar em interação novos modos de fazer e de compreender, "no quadro de práticas socialmente organizadas" (2008, p.149). Essa diversidade epistemológica se beneficiará também da troca e o confronto de pontos de vista, de maneiras de significar e de fazer já enraizados, levando-os a questionar esse enraizamento e a propor possibilidades de produção de novo conhecimento. Para retomar a questão colocada por Frigotto (2008), impõese como imperativo tratar essas questões colocando em enfrentamento os muitos e conflitantes saberes sobre seus objetos e se colocando como problema o desenho dos modos interdisciplinares de tratá-los. As questões aqui tratadas só se configuram como objetos de saber neste território, nesta conjuntura e neste momento histórico (só produzem sentido e só encontram interlocução num programa de pesquisa que se ocupe das dinâmicas territoriais na Amazônia). 


\title{
TERRITORIAL DYNAMICS AND SOCIETY: AN EXPERIENCE OF INTERDISCIPLINARY GRADUATE IN THE AMAZON REGION
}

\begin{abstract}
This paper presents an initial experience of a graduate program in northern Brazil. It presents the conceptual basis of the program, an observation of the regional context and, based on documental analysis, some reflections on students' profiles and the issues addressed. The program's purpose is to study in an interdisciplinary approach territorial dynamics that shape the region. The issues addressed focus on the socioeconomic dynamics in relation with local power, public policy, great projects, resistance movements, knowledge and discourses produced in these relationships.

Keywords: Interdisciplinarity. Social dynamics. Territory. Amazon.
\end{abstract}

\section{DINÁMICAS TERRITORIALES $Y$ SOCIEDAD: UNA EXPERIENCIA DE POSGRADO INTERDISCIPLINAR EN LA REGIÓN AMAZÓNICA}

\section{Resumen}

Este artículo presenta una experiencia inicial de un programa de posgrado en el norte de Brasil. Se presentan las bases conceptuales del programa, una lectura del contexto regional y, basado en un análisis documental, una primera reflexión sobre el perfil del participante y los temas abordados. El propósito del programa es estudiar, en un enfoque interdisciplinar, dinámicas territoriales que conforman la región.Los temas tratados se centran en las dinámicas socio-económicas en relación con la política pública local, los grandes proyectos, los movimientos de resistencia y el conocimiento y los discursos producidos en estas relaciones.

Palabras clave: Interdisciplinariedad. Dinámica social. Territorio. Región Amazónica. 


\section{REFERÊNCIAS}

ALMEIDA, A. W. B. de. O intransitivo da transição. O Estado, os conflitos agrários e a violência na Amazônia. In: LENA P.; OLIVEIRA A. E. de. (Org.). Amazônia: fronteira agrícola 20 anos depois. Belém: MPEG / ORSTOM, 1991.

ARAGON, L. E. e MOUGET, L. J. A. (org.) Migrações Internas na Amazônia: contribuições teóricas e metodológicas. Belém: NAEA-UFPA, 1986.

BARDIN, L. Análise de conteúdo. Lisboa: Edições 70, 1979.

BECKER, B. K. Amazônia: geopolítica na virada do III milênio. Rio de Janeiro: Garamond, 2006.

BEZERRA, R. L. Terceirização das relações de trabalho em Carajás: entre a flexibilização e a precariedade? Projeto de mestrado. Programa de Pós-Graduação em Dinâmicas Territoriais e Sociedade na Amazônia. UFPA, Campus de Marabá, 2012.

BRANDÃO, C. Território e Desenvolvimento: as múltiplas escalas entre o local e o global. Campinas: Ed. UNICAMP, 2007.

BRESSAN, L. R. Estado, políticas públicas e agricultura familiar: o papel estruturante do PNAE na consolidação de lógicas familiares de produção no sudeste paraense. Projeto de mestrado. Programa de Pós-Graduação em Dinâmicas Territoriais e Sociedade na Amazônia. UFPA, Campus de Marabá, 2012.

CASTRO, E.; MOURA, E. A.; MAIA, M. L. S., Industrialização e Grandes Projetos: Desorganização e Reorganização do Espaço. Belém: UFPA, 1995.

COSTA, F. A. Ecologismo e Questão Agrária na Amazônia. Belém: NAEA/UFPA, 1992.

COSTA, F. A. Questão Agrária e Macropolíticas na Amazônia: novos momentos, grandes desafios. Revista de Estudos Avançados. São Paulo: IEA/USP, $n^{\circ} 53$, jan-mar 2005. 
DEAN, W. O Brasil e a Luta pela Borracha. São Paulo: Nobel, 1989.

FAZENDA, I. C. A. Interdisciplinaridade: história, teoria e pesquisa. Campinas-SP: Papirus, 1984.

FERNANDES, B. M. Movimentos socioterritoriais e movimentos socioespaciais: contribuição teórica para uma leitura geográfica dos movimentos sociais. Revista Nera. Presidente Prudente, ano 8, n.6, jan-jun. 2005, p.14-32.

FRIGOTTO, G. A interdisciplinaridade como necessidade e como problema nas ciências sociais. Ideação.Revista do Centro de Educação e Letras. vol.10, n1. jul/dez 2008, p.41-62. Disponível em: http://erevista.unioeste.br/index.php/ideacao/article/viewArticle/4143. Acesso em: 25 abr. 2013.

GONÇALVES, C. W. P. Amazônia, Amazônias. São Paulo: Contexto, 2001.

HAESBAERT, R. O Mito da Desterritorialização: do "fim dos territórios" à multiterritorialidade. Rio de Janeiro: Bertrand Brasil, 2004.

HAESBAERT, R. Territórios Alternativos. São Paulo: Contexto, 2011.

HÉBETTE, J. A Resistência dos Posseiros. In: HÉBETTE, J. A. Cruzando a Fronteira: 30 anos de estudo do campesinato na Amazônia. Belém: EDUFPA, 2004.

HECHT, S. e COCKBURN, A. The Fate of the Forest. Developers, Destroyers and Defenders of the Amazon. New York: Harper Collins, 1990.

IKEDA, J. C. O. Projeto Amazônia: o Grande Carajás e seus impactos na organização política do município de Marabá, Pará. Projeto de mestrado. Programa de Pós-Graduação em Dinâmicas Territoriais e Sociedade na Amazônia. UFPA, Campus de Marabá, 2012.

IANNI, O. Colonização e contra-reforma agrária na Amazônia. Petrópolis: Vozes, 1979.

LEIS, H. R. Sobre o conceito de interdisciplinaridade. Cadernos de Pesquisa Interdisciplinar em Ciências Humanas. n. 73, ago 2005, p.2-23. 
LENOIR, Y. Didática e interdisciplinaridade: uma complementaridade necessária e incontornável. In: FAZENDA, I.C.A (org.). Didática e Interdisciplinaridade.

Campinas-SP: Papirus, 1998.

LISBOA, F. M. Análise discursiva das propagandas eleitorais do plebiscito para a divisão do Pará. Projeto de mestrado. Programa de Pós-Graduação em

Dinâmicas Territoriais e Sociedade na Amazônia. UFPA, Campus de Marabá, 2012.

MARTINS, J. de S. Os Camponeses e a Política no Brasil. Petrópolis: Vozes, 1981.

MARTINS, R. N. Toyotizar o currículo: noções/categorias na Educação Técnica do Campus Industrial do Instituto Federal do Pará em Marabá. Projeto de mestrado.

Programa de Pós-Graduação em Dinâmicas Territoriais e Sociedade na Amazônia. UFPA, Campus de Marabá, 2012.

MELLO, J. M. C. de. O Capitalismo Tardio: contribuição à revisão crítica da formação e do desenvolvimento da economia brasileira. São Paulo: Brasiliense, 1982.

RIBEIRO JR., R. Gaviões Akrãtikatêjê: trajetória e constituição de uma identidade no processo de dominação e resistência. Projeto de mestrado. Programa de PósGraduação em Dinâmicas Territoriais e Sociedade na Amazônia. UFPA, Campus de Marabá, 2012.

RUSSI, A. Cidade subversiva: a desobediência civil como forma de garantir a aplicação dos dispositivos constitucionais do direito à moradia e da dignidade da pessoa humana em um estado democrático de direito. Projeto de mestrado.

Programa de Pós-Graduação em Dinâmicas Territoriais e Sociedade na Amazônia. UFPA, Campus de Marabá, 2012.

SÁ-SILVA, J. R.; ALMEIDA, C. D.; GUINDAN, J. F. Pesquisa documental: pistas teóricas e metodológicas. Revista Brasileira de História \& Ciências Sociais . Ano I, nº I, jul. 2009.

SANTOS, B. S. A gramática do tempo: para uma nova cultura política. São Paulo: Cortez, 2008. 
SANTOS, R. O. História Econômica da Amazônia (1800-1920). São Paulo: T.A. Queirós. 1980.

SANTOS, M. O retorno do território. In: Observatório Social de América Latina. Año 6, n. 16 (jun-2005) Buenos Aires, CLACSO, 2005. p.255-261. Disponível em: http://bibliotecavirtual.clacso.org.ar/ar/libros/osal/osal16/D16Santos.pdf. Acesso em: 01 jun. 2015.

SCHMINK, M. e WOOD, C. H. Contested Frontiers in Amazonia. New York: Columbia University Press, 1992.

SENA, L. R. A construção de sentido acerca do Movimento dos Trabalhadores Rurais Sem Terra/MST no discurso da imprensa escrita paraense. Projeto de mestrado. Programa de Pós-Graduação em Dinâmicas Territoriais e Sociedade na Amazônia. UFPA, Campus de Marabá, 2012.

SILVA, C. B. Territorialidades em conflito na dinâmica da região sudeste do Pará: a UHE de Marabá como possibilidade de uma cultura civilizacional? Projeto de mestrado. Programa de Pós-Graduação em Dinâmicas Territoriais e Sociedade na Amazônia. UFPA, Campus de Marabá, 2012.

SOUZA, A. S. Dinâmica territorial e trabalho na Amazônia: análise sobre o Município de Parauapebas a partir da Empresa Vale e da migração de trabalhadores nordestinos. Projeto de mestrado. Programa de Pós-Graduação em Dinâmicas Territoriais e Sociedade na Amazônia. UFPA, Campus de Marabá, 2012.

SOUZA, V. M. Território e identidade: a percepção dos diversos atores sobre o território das mulheres quebradeiras de coco babaçu no município de São Domingos do Araguaia, Pará. Projeto de mestrado. Programa de Pós-Graduação em

Dinâmicas Territoriais e Sociedade na Amazônia. UFPA, Campus de Marabá, 2012.

SOUZA, M.A.A. Apresentação: Milton Santos, um revolucionário. . In: Observatório Social de América Latina. Año 6, n. 16 (jun-2005) Buenos Aires, CLACSO, 2005. p.251-254. Disponível em:

http://bibliotecavirtual.clacso.org.ar/ar/libros/osal/osal16/D16Santos.pdf. Acesso em: 01.jun. 2015.

TEIXEIRA JR., T.R. Fazendo as pazes com a natureza? Um estudo sobre a implantação do projeto "município verde" em Paragominas, Estado do Pará. Projeto de mestrado. Programa de Pós-Graduação em Dinâmicas Territoriais e Sociedade na Amazônia. UFPA, Campus de Marabá, 2012. 
UNIVERSIDADE FEDERAL DO PARÁ. Programa de Pós-Graduação em Dinâmicas Territoriais e Sociedade na Amazônia. Marabá, 2012.

VAL, A. L. Formação e fixação de recursos humanos: ações essenciais para a Amazônia. Cienc. Cult., São Paulo, v. 58, n. 3, Set. 2006 . Disponível em: http://cienciaecultura.bvs.br/scielo.php?script=sci arttext\&pid=S000967252006000300017\&lng=en\&nrm=iso. Acesso em: 24 abr. 2013.

VELHO, O. G. Frentes de Expansão e Estrutura Agrária: estudo do processo de penetração numa área da Transamazônica. Rio de Janeiro: Zahar, 1972.

Artigo:

Submetido em 30.10.2014

Aceito em 29.06.2015 